\title{
Evaulation of miRNAs as a Non-invasive Blood- Based Marker for Detection of Colorectal Cancer
}

\section{Mohamed Fakhry}

Al-Azhar University Faculty of Medicine

\section{Huda Mohamed}

Qus central hospital

\section{Mona Mohamed}

Al-Azhar University Faculty of Medicine

\section{Sara Adel}

Al-Azhar University Faculty of Medicine

\section{Mohammed Tag-Adeen}

South Valley University

Marwa El-Sayed ( $\square$ nooreleiman1@yahoo.com )

South Valley University https://orcid.org/0000-0003-4864-6858

\section{Hamdy Mahfouz}

Al-Azhar University Faculty of Medicine

\section{Research article}

Keywords: miRNAs, CRC, screening, gene expression

Posted Date: June 28th, 2021

DOl: https://doi.org/10.21203/rs.3.rs-634213/v1

License: (c) (1) This work is licensed under a Creative Commons Attribution 4.0 International License.

Read Full License 


\section{Abstract}

Backgrounds: Although Colorectal cancer accounts for over $10 \%$ of all cancer incidence, it is highly preventable and can be detected at a stage when there are often no symptoms. The American Society for Gastrointestinal Endoscopy encourages everyone over 50 to be screened for colorectal cancer, but many should start much earlier due to health and family history. Minimally invasive tests will be superior overtime taking into consideration availability, costs, convenience, and patient-clinicians preferences.

Methods: 50 patients with known colorectal cancer (CRC) were enrolled based on colonoscopic and histopathological findings and 25 healthy subjects were enrolled as control group. Level of microRNA-21 gene expression was measured in both groups.

Results: Level of microRNA-21 gene expression was significantly higher among CRC group in comparison to control group $(2.76 \pm 0.56$ vs. $0.71 \pm 0.16(\mathrm{u} / \mathrm{l}) ; \mathrm{P}<0.001)$. A cut off point $>1.09 \mathrm{u} / \mathrm{l}$, microRNA-21 gene expression had $96 \%$ sensitivity and $95 \%$ specificity with area under curve was 0.95 for detection of colorectal cancer. Level of microRNA-21 gene expression was significantly higher among CRC group in comparison to control group and its level was increasing with those with metastasis.

Conclusion: Level of microRNA-21 gene expression is useful biomarker for discriminating CRC patients from healthy people.

\section{Introduction}

Colorectal cancer (CRC) as the third most common solid cancer, representing $10 \%$ of all cancers, is a major cause of morbidity and mortality around the world. Cancer of the colon is the fifth most common cancer diagnosed in both men and women, while cancer of the rectum is the eighth most incident $[1,2]$.

Regarding mortality, the CRC is the second leading cause of cancer-related deaths worldwide, with about 915,880 deaths estimated for 2020 while Colon cancer is the fifth most deadly cancer with 576,858 deaths, representing $5.8 \%$ of all cancer deaths [1].

Incidence of CRC is increasing worldwide by $60 \%$, except in highly developed countries where there is recent declining trends, by the year 2030. The increasing trend of CRC seems to multifactorial related to economic change, dietary patterns, smoking, alcohol consumption, processed food. Adding all these factors to sedentary life eventually ends with overweight and obesity [3].

Advance in CRC screening and treatment cause remarkable decreases in incidence and mortality. Well established organized screening program and early detection using colonoscopies, flexible sigmoidoscopies, computed tomography (CT) colonography, faecal immunochemistry, and faecal occult blood testing have largely improved survival in highly developed countries.[4]. 
The 5-year survival for patients with early-stage CRC is nearly $90 \%$ which drops to $8 \%$ for advanced disease, early detection will increase the chance of curative treatment with minimal morbidity and mortality [5].

Colonoscopy has been widely regarded as the gold standard for detecting CRC even though its effects on reducing CRC incidence and mortality has never been proved in a randomized control trial. Although colonoscopy has high sensitivity and specificity with opportunity to detect and resect lesion, it has several limitations such as invasive nature, not easily affordable and a bothering bowel preparation. Additionally, its success depends on the training level and experience of the operators. Thus, its widespread application for CRC in large-scale screening is hampered [6, 7].

On the other hand, less-invasive diagnostic methods, such as fecal occult blood testing (FOBT) [8] and carcinoembryonic antigen (CEA) screening [9] in blood are of limited value owning to poor sensitivity and specificity $[10,11]$. New noninvasive approaches like fecal DNA testing, methylated SEPT9 test and microRNAs test are promising $(7,12)$

Several studies have highlighted the potential role of microRNAs (non-coding RNAs that posttranscriptionally regulate gene expression) to discriminate CRC patients from healthy controls and serve as novel biomarkers for CRC screening with high accuracy [12-14]. However, these results lack consistencies with even opposite results for the same miRNAs which could be due to different research methods and tested populations between laboratories.

The aim of this work is to evaluate microRNAs as a non-invasive blood-based marker for detection of colorectal cancer

\section{Patients And Methods}

\section{Study design and time:}

A case control study carried out on 75 subjects divided into 2 groups, group I: 25 healthy control and group II: 50 patients presented with bleeding per rectum, abdominal pain, constipation who admitted to Hepatology\& Gastroenterology and Infectious diseases department Al-Azhar University Hospital and Shefaa Al Orman Hospital in the period from April 2019 to April 2020.

\section{Inclusion criteria:}

Adult patients of both sexes with colorectal cancer, diagnosed by colonoscopy and confirmed by histopathology.

\section{Exclusion criteria:}

Patients with other malignancies anywhere in the body, except those with colorectal cancer and lymphatic or distant metastasis. 
Patients with colorectal cancer with previous surgical intervention or on chemotherapy

Patients with Inflammatory bowel diseases.

\section{Laboratory study:}

After full medical history and complete clinical examination, the following tests were done:

- Liver function test (Alanine transaminase (ALT), Aspartate transaminase (AST), alkaline phosphatase (ALP), bilirubin, serum albumin)

- Prothrombin time (PT) \& international normalization ratio (INR).

- Complete blood count.

- CEA by ELISA

- CA 19 - 9 by ELISA

- Serum microRNA $215 p$

\section{microRNA assay:}

Whole blood EDTA samples were used for microRNA extraction. The miRNeasy (LOT number: 160047780; Qiagen, Germany) were used to extract miRNAs from EDTA samples.

Reverse transcription of $4 \mu \mathrm{l}$ whole blood RNA were performed using miScript RT kit (Catalog number :218160 Qiagen, Germany). Reverse transcription and quantitative Real-Time-Polymerase Chain Reaction (qRT-PCR) analysis were performed with miScript SYBR Green PCR kit (QIAGEN, catalog number : 218037, Germny). using synthesized primers from QIAGEN (LOT number : 201812210009 and 201812130249). miRNAs were detected in accordance with the manufacturer's instructions. The amplification conditions for miRNAs were as follows: $10 \mathrm{~min}$ at $95^{\circ} \mathrm{C}, 45$ cycles of $10 \mathrm{~s}$ at $95^{\circ} \mathrm{C}, 20 \mathrm{~s}$ at $60^{\circ} \mathrm{C}, 1 \mathrm{~s}$ at $72^{\circ} \mathrm{C}$. Samples were normalized to U6. Relative miRNA expression was calculated using the power formula: $2-\triangle C T(\triangle C T$ = CTmiRNA-CTU6). The primers were cited by several published documents, they are; miR-21 (forward, GGACTAGCTTATCAGACTG; reverse, CATCAGATGCGTTGCGTA) and U6-snRNA (forward, ATTGGAACGATACAGAGAAGAT; reverse, GGAACGCTTC ACGAATTT) 18.

\section{Imaging study}

Abdominal ultrasound was done in all patients

Triphasic pelviabdominal CT scan with contrast after fasting for staging and search for secondaries (exclusion of patients whose serum creatinine more than 1.5).

\section{Colonoscopy:}

Endoscopic examination of large bowel with flexible fiberoptic colonoscopy for diagnosis, staging and biopsy for histopathological examination was done after good preparation and fasting under sedation 
with midazolam. Eating any solids were not allowed the day before the procedures, only liquids. Patients can't drink or eat anything 6 hours before the procedure. Strong laxatives with large doses were taken.

\section{Ethical considerations}

Approval of the study was obtained from the Research Ethics Committees in Al Azhar Faculty of Medicine, Orman hospital. An informed consent was obtained from all participants after explanation of the details of the study.

\section{Statistical analysis}

Statistical analysis was done using SPSS version 22 (IBM SPSS Inc., Chicago, US). Baseline demographic, clinical, and laboratory characteristics were recorded as numbers and percentage for categorical data and means and standard deviation for continuous data.

Student's T-test was used to compare results of continuous variables between groups and Chi square test for categorical variables. Pearson correlation was used to assess the correlation miRNA-21 gene expression with other variables.

Diagnostic accuracy of different parameters in prediction of colorectal cancer and presence of liver metastasis and advanced TNM stage was assessed by receiver operating characteristics curve. P value was considered significant if $<0.05$.

\section{Results}

The study enrolled (50) patients with known colorectal cancer (CRC) based on colonoscopy and histopathological findings and 25 healthy subjects were enrolled as control group.As shown in Table (1) mean age of enrolled patients with CRC was $46.74 \pm 11.65$ years and majority of them was smokers and males. Mean age of the control group was $49.08 \pm 12.22$ years and majority of them was males. Both groups had no significant differences as regard demographic data $(P>0.05)$. Mean size of the lesion among enrolled patients with CRC was $4.86 \pm 1.51 \mathrm{~cm}$ and most of the lesions was $<5 \mathrm{~cm}$. Out of the studied lesions: $72 \%$ of lesion presents in the colon. Based on TNM staging system; $72 \%$ patients had IIIIV stage.64\%patients had differentiated adenocarcinoma. Distant metastasis was absent in majority of patients (Table 2, Supplementary Fig. 1). 
Table 1

Demographic data of enrolled groups

\begin{tabular}{|llll|}
\hline & Cases $(\mathbf{n}=\mathbf{5 0})$ & Control $(\mathbf{n}=\mathbf{2 5})$ & P value \\
\hline Age (years) & $46.74 \pm 11.65$ & $49.08 \pm 12.22$ & 0.42 \\
Sex & $36(72 \%)$ & $19(76 \%)$ & 0.46 \\
Male & $14(28 \%)$ & $6(24 \%)$ & \\
Female & & & 0.47 \\
Smoking & $26(52 \%)$ & $12(48 \%)$ & 0.55 \\
\hline Family history of CRC & $9(18 \%)$ & $4(16 \%)$ & \\
\hline \multicolumn{2}{|l}{ Data expressed as frequency (percentage), mean (SD). P value was significant if $<0.05$} \\
\hline
\end{tabular}


Table 2

Characteristics of the lesions among the enrolled patients

\begin{tabular}{|ll|}
\hline & $\mathbf{N}=\mathbf{5 0}$ \\
\hline Size $(\mathrm{cm})$ & $4.86 \pm 1.51$ \\
$>5 \mathrm{~cm}$ & $38(76 \%)$ \\
\hline Site of the lesion & $12(24 \%)$ \\
Colon & $36(72 \%)$ \\
Rectum & $14(28 \%)$ \\
\hline TNM stage & $14(28 \%)$ \\
I-II & $36(72 \%)$ \\
\hline III-IV & $32(64 \%)$ \\
\hline Histological type & $18(36 \%)$ \\
Differentiated & \\
\hline Undifferentiated & $19(38 \%)$ \\
\hline Lymph metastasis & $42(84 \%)$ \\
\hline Distant metastasis & $5(10 \%)$ \\
Absent & $3(6 \%)$ \\
Liver metastasis & \\
\hline Peritoneal metastasis & \\
\hline Data expressed as frequency (percentage), mean (SD) \\
\hline
\end{tabular}

level of miRNA-21 gene expression was significantly higher among CRC group in comparison to control group ( $2.76 \pm 0.56$ vs. $0.71 \pm 0.16(\mathrm{u} / \mathrm{l}) ; \mathrm{P}<0.001)$ (Table 3). Lesion with size exceeded $5 \mathrm{~cm}$ had significantly higher miRNA-21 gene expression in comparison to those with size $<5 \mathrm{~cm}(3.87 \pm 0.62 \mathrm{vs}$. $2.73 \pm 2.73(\mathrm{u} / \mathrm{l}) ; \mathrm{P}=0.03)$. Also, those with TNM stage $\mathrm{I}-\mathrm{II}$ had significantly lower miRNA-21 gene expression in comparison to those with III-IV stage ( $3.76 \pm 0.55$ vs. $2.70 \pm 0.59(\mathrm{u} / \mathrm{I}) ; \mathrm{P}=0.04)$. Patients with liver metastasis had significantly higher miRNA-21 gene expression in comparison to those without liver metastasis $(3.70 \pm 0.23$ vs. $2.89 \pm 0.23(\mathrm{u} / \mathrm{l}) ; \mathrm{P}=0.01)$. Other clinicopathological parameters were not statistically significant (Table 4, Supplementary Fig. 2). 
Table 3

Level of miRNA-21 gene expression among enrolled groups

\begin{tabular}{|lcll|}
\hline & Cases $(\mathbf{n}=\mathbf{5 0})$ & Control $(\mathbf{n}=\mathbf{2 5})$ & P value \\
\hline MiRNA-21 $(\mathrm{u} / \mathrm{l})$ & $2.76 \pm 0.56$ & $0.71 \pm 0.16$ & $<0.001$ \\
Range & $1.50-3.70$ & $0.40-1$ & \\
\hline \multicolumn{2}{|l}{ Data expressed as mean $(\mathrm{SD})$, range. $P$ value was significant if $<0.05}$. \\
\hline
\end{tabular}


Table 4

miRNA-21 expression in patients based on clinicopathological parameters

\begin{tabular}{|lll|}
\hline & Mean \pm SD & P value \\
\hline Size $(\mathrm{cm})$ & $2.73 \pm 2.73$ & 0.03 \\
$<5 \mathrm{~cm}$ & $3.87 \pm 0.62$ & \\
$>5 \mathrm{~cm}$ & & 0.62 \\
\hline Site of the lesion & $2.74 \pm 0.58$ & \\
Colon & $2.82 \pm 0.52$ & \\
Rectum & & 0.04 \\
\hline TNM stage & $2.70 \pm 0.59$ & \\
I-II & $3.76 \pm 0.55$ & 0.96 \\
III-IV & & \\
\hline Histological type & $2.76 \pm 0.59$ & \\
Differentiated & $2.76 \pm 0.50$ & \\
Undifferentiated & & 0.33 \\
\hline Lymph metastasis & $2.67 \pm 0.46$ & \\
Yes & $2.82 \pm 0.62$ & 0.01 \\
No & & \\
\hline Liver metastasis & $3.70 \pm 0.23$ & \\
Yes & $2.89 \pm 0.23$ & \\
No & & \\
\hline Peritoneal metastasis & $2.70 \pm 0.31$ & \\
Yes & & \\
No & & \\
\hline Data expressed as frequency (percentage) & \\
\hline
\end{tabular}


Table 5

Performance of different markers in detection of CRC

\begin{tabular}{|llcl|}
\hline Indices & miRNA-21 & CA19-9 & CEA \\
\hline Sensitivity & $96 \%$ & $30 \%$ & $59 \%$ \\
\hline Specificity & $95 \%$ & $89 \%$ & $76 \%$ \\
\hline Positive predictive value & $98 \%$ & $71 \%$ & $66 \%$ \\
\hline Negative predictive value & $92 \%$ & $41 \%$ & $54 \%$ \\
\hline Cut off point & $>1.09$ & $>35$ & $>25$ \\
\hline Area under curve & 0.95 & 0.54 & 0.83 \\
\hline CRC: colo-rectal cancer; CEA: carcino-embryonic an & \\
\hline
\end{tabular}

As shown in Table (5) a cut off point $>1.09 \mathrm{u} / \mathrm{l}$, miRNA-21 gene expression had $96 \%$ sensitivity and $95 \%$ specificity with area under cure was 0.95 for detection of colo-rectal cancer.It was noticed that CA19-9 at cut of $>35 \mathrm{ng} / \mathrm{dl}$ had $30 \%$ sensitivity and $89 \%$ specificity with area under cure was 0.54 for detection of colo-rectal cancer while CEA at cut off $>25 \mathrm{ng} / \mathrm{dl}$ had $59 \%$ sensitivity and $76 \%$ specificity with area under cure was 0.83 for detection of colo-rectal cancer (Supplementary Fig. 3).

A cut off point $>2.67 \mathrm{u} / \mathrm{l}$, miRNA-21 gene expression had $100 \%$ sensitivity and $50 \%$ specificity with area under curve (AUC) was 0.89 for detection of liver metastasis in patients with colo-rectal cancer.

It was noticed that CA19-9 at cut of $>39 \mathrm{ng} / \mathrm{dl}$ had $60 \%$ sensitivity and $86 \%$ specificity with area under curve was 0.59 for detection of liver metastasis while CEA at cut off $>19 \mathrm{ng} / \mathrm{dl}$ had $80 \%$ sensitivity and $30 \%$ specificity with area under curve was 0.53 for detection of liver metastasis (Table 6, Supplementary Fig. 4).

Table 6

Performance of different markers in detection of liver metastasis

\begin{tabular}{|llll|}
\hline Indices & miRNA-21 & CA19-9 & CEA \\
\hline Sensitivity & $100 \%$ & $60 \%$ & $80 \%$ \\
\hline Specificity & $87 \%$ & $86 \%$ & $30 \%$ \\
\hline Positive predictive value & $50 \%$ & $23 \%$ & $45 \%$ \\
\hline Negative predictive value & $100 \%$ & $97 \%$ & $70 \%$ \\
\hline Cut off point & $>2.67$ & $>39$ & $>19$ \\
\hline Area under curve & 0.89 & 0.59 & 0.53 \\
\hline
\end{tabular}


A cut off point $>3 \mathrm{u} / \mathrm{l}$, miRNA-21 gene expression had $100 \%$ sensitivity and $84 \%$ specificity with area under curve was 0.95 for detection of advanced TNM stage (stage III-IV) in patients with colo-rectal cancer.It was noticed that CA19-9 at cut of $>34 \mathrm{ng} / \mathrm{dl}$ had $41 \%$ sensitivity and $84 \%$ specificity with area under curve was 0.57 for detection of advanced TNM stage while CEA at cut off $>13 \mathrm{ng} / \mathrm{dl}$ had $80 \%$ sensitivity and $76 \%$ specificity with area under curve was 0.79 for detection of advanced TNM stage (Table 7, Supplementary Fig. 5).

Table 7

\begin{tabular}{|llll|}
\hline Performance of different markers in advanced TNM stage \\
\hline Indices & miRNA-21 & CA19-9 & CEA \\
\hline Sensitivity & $100 \%$ & $41 \%$ & $80 \%$ \\
\hline Specificity & $84 \%$ & $84 \%$ & $76 \%$ \\
\hline Positive predictive value & $42 \%$ & $71 \%$ & $75 \%$ \\
\hline Negative predictive value & $100 \%$ & $61 \%$ & $78 \%$ \\
\hline Cut off point & $>2.67$ & $>34$ & $>13$ \\
\hline Area under curve & 0.89 & 0.57 & 0.79 \\
\hline
\end{tabular}

\section{Discussion}

Early detection of tumor improves the overall survival rate of CRC patients, which highlights an urgent need to find specific, sensitive, and non-aggressive molecular biomarkers suitable for the early diagnosis of CRC. In recent years, there has been an increased interest in finding prognostic biomarkers for CRC to evaluate the expression profiles of single or multiple miRNA in tumor tissues $[15,16,17]$.

Several clinical studies in CRC patients showed that a large number of miRNAs are actively involved in carcinogenesis, cancer development, and progression, by acting both as oncogenes (i.e., miR-20a, miR-21, miR-31, miR-92, miR-181b) or as tumor suppressors (i.e., miR143 and miR-145) [18]. Although a limited number of studies have explored the potential role of tissue expression of miR-21, no information has been provided about the diagnostic performance of plasma miR-21in CRC patients [19].

The current study assessed role of miRNA-21 gene expression as a non-invasive blood-based marker for detection of colorectal cancer. Mean age of enrolled patients with CRC was $56.74 \pm 11.65$ years and majority $(72 \%)$ of them was males. This result was consistent with the results of a study by [20] who reported that their studied cases had a mean age of $50.6 \pm 15.1 \mathrm{ys}$. Also, many previous studies revealed that male had higher frequency to develop CRC [21] while other reported that both sexes are equally affected [22].

Several studies that were done over the years evaluating the former miRNAs studied in CRC patients but of different ethnic origins as part of different miRNAs panels. These studies have demonstrated that 
miRNA-21 and miRNA-17 92 cluster members, including miRNA18a and miRNA-92a, were increased in the serum of CRC patients making them useful biomarkers for discriminating CRC patients from healthy controls [23].

In contrast, results concerning serum miRNA-21 levels have revealed its significant down-regulation in $\mathrm{CRC}$ patients compared to healthy control group. The reasons for these contradictory results with the present study may be related to the different studied populations [24].

Interestingly, On the other hand, miRNA 21 expressions in patients with CRC and adenoma was found to be increased in tissue samples [16]. Also, it was upregulated in the tissue of 18 adenoma patients compared with the paired adjacent non-adenoma tissue. In addition, expression of miRNA 21 was found to be lower in adenomas than in cancer tissue and positively related to CRC stage [25].

The sensitivity and specificity of miR-21 expression levels, as a CRC molecular biomarker, were assessed in the serum of CRC patients using ROC curve analysis. At cut off point $>1.09 \mathrm{u} / \mathrm{l}$, miRNA-21 gene expression had $96 \%$ sensitivity and $95 \%$ specificity with area under curve was 0.95 for detection of colorectal cancer. MiR-21 expression levels in serum showed high sensitivity and specificity, so had a significant diagnostic value for CRC patient.

In line with the current study, Ghareib et al. [26] found that the serum miR-21 expression level could be considered as a promising marker for the diagnosis of CRC patients with a sensitivity and specificity of $95.8 \%$ and $91.7 \%$, respectively (an area under the ROC curve, AUC 0.94). Also, serum miR-21 expression level had sensitivity and specificity of $84 \%$ and $90 \%$, respectively with $87 \%$ accuracy for detection of CRC at cut of $>2.80 \mathrm{u} / \mathrm{I}[27]$.

In another study, the sensitivity and specificity of serum miR-21 expression levels were $82.8 \%$ and $90.6 \%$ for CRC detection, respectively[16].

Based on the current results and previously reported studies, serum microRNA-21 might serve as noninvasive diagnostic markers in CRC.

Level of miRNA-21 was significantly increasing with the size and advancing stage of the CRC. In line with the current results, many previously reported studies indicated that the miR-21 expression level is increased in different stages of CRC, from the early to later stages $[26,28]$. This comes in agreement with Schetter et al. [25] who found that higher expression levels of miRNA 21 were associated with more advanced clinical stages of CRC. But Bastaminejad et al. [29] found no obvious differences were detected in miR-21 expression levels between stages III/IV, while a significant increase was found between stages I/II. This difference could be attributed to the number of cases studied in each stage.

Also, miRNA-21 gene expression could predict advanced stages of CRC. Bastaminejad et al. [29] showed that serum miR-21 expression levels were able to reliably distinguish TNM stages III and IV from stages I and II, with a sensitivity of $88.10 \%$ and a specificity of $73.68 \%$ (AUC: 0.794 ). CEA and CA19-9 have been reported to be of low specificity and sensitivity, data from a single center study showed that the AUC of 
serum miRNA for early CRC diagnosis was significantly higher than that of combined tumor markers (CEA and CA19-9) (0.854 vs. 0.613) [30]. When using $2.5 \mathrm{mg} / \mathrm{ml}$ of the serum CEA as the upper limits of normal, the sensitivity for Dukes' A and B lesions is only $36 \%$, compared with $74 \%$ for Dukes' $C$ and $83 \%$ for Dukes' D disease [17].

This study was limited by relatively small sample size high cost and different research methods and tested populations between laboratories.

\section{Conclusion}

The results of this study suggested that miR-21 expression level in serum could be considered as a valuable marker for CRC diagnosis. However, the evaluation of the studied microRNAs in patients with early stage $\mathrm{CRC}$ is required to evaluate the role of these markers for early diagnosis, which will contribute to early management of patients and improve the disease outcome.

\section{Declarations}

Data Availability: All data generated or analysed during this study are included in this published article (and its Supplementary Information file).

Competing Interests: The authors declare no competing interests.

Funding: No funding sources

Author Contributions: M.F., Huda Mohamed, M.M., and Hamdy Mahfouz. conceived and designed the experiments. M.T, M.E, Huda Mohamed, S.A. performed the experiments. M.T, M.E., Huda Mohamed, M.F. analysed the data. M.E., M.M., and Hamdy Mahfouz. wrote the main manuscript text.

\section{References}

1. Sung H, Ferlay J, Siegel RL, Laversanne M, Soerjomataram I, Jemal A, Bray F. Global cancer statistics 2020: GLOBOCAN estimates of incidence and mortality worldwide for 36 cancers in 185 countries. CA Cancer J Clin. 2021;71(3):209-49.

2. Ferlay J, Ervik M, Lam F, et al. Global Cancer Observatory: Cancer Today. Lyon, France: International Agency for Research on Cancer; Available from: https://gco.iarc.fr/today, Accessed 30 May 2021.

3. Arnold M, Sierra MS, Laversanne M, Soerjomataram I, Jemal A, Bray F. Global patterns and trends in colorectal cancer incidence and mortality. Gut. 2017;66(4):683-91.

4. Edwards BK, Ward E, Kohler BA, Eheman C, Zauber AG, Anderson RN, Jemal A, Schymura MJ, Lansdorp-Vogelaar I, Seeff LC, van Ballegooijen M, Goede SL, Ries LA. Annual Report to the Nation on the Status of Cancer, 1975-2006, Featuring Colorectal Trends and Impact of Interventions (Risk Factors, Screening, and Treatment) to Reduce Future Rates. Cancer. 2010; 116(3):544 - 73. 
5. Akkoca AN, Yanik S, Ozdemir ZT, Cihan FG, Sayar S, Cincin TG, Cam A, Ozer C. TNM and Modified Dukes staging along with the demographic characteristics of patients with colorectal carcinoma. Int J Clin Exp Med. 2014;7:2828-35.

6. Lieberman D. Colorectal Cancer Screening with Colonoscopy. JAMA INTERN MED. 2016;176:903-4.

7. Iyad A, Issa M, Noureddine. Colorectal cancer screening: An updated review of the available options. World J Gastroenterol. 2017;23(28):5086-96.

8. Bretthauer M. Colorectal cancer screening. J Intern Med. 2011;270:87-98.

9. De Maio G, Rengucci C, Zoli W, Calistri D. Circulating and stool nucleic acid analysis for colorectal cancer diagnosis. World J Gastroenterol. 2014;20:957-67.

10. Ransohoff DF, Sox HC. Clinical Practice Guidelines for. Colorectal Cancer Screening: New Recommendations and New Challenges. JAMA. 2016;315:2529-31.

11. Knudsen AB, Zauber AG, Rutter CM, Naber SK, Doria-Rose VP, Pabiniak C, Johanson C, Fischer SE, Lansdorp-Vogelaar I, Kuntz KM. Estimation of Benefits, Burden, and Harms of Colorectal Cancer Screening Strategies: Modeling Study for the US Preventive Services Task Force. JAMA. 2016;315:2595-609.

12. Yamada A, Horimatsu T, Okugawa Y, Nishida N, Honjo H, Ida H, Kou T, Kusaka T, Sasaki Y, Yagi M, Higurashi T, Yukawa N, Amanuma Y, Kikuchi O, Muto M, Ueno Y, Nakajima A, Chiba T, Boland CR, Goel A. Serum miR-21, miR-29a, and miR-125b Are Promising Biomarkers for the Early Detection of Colorectal Neoplasia. Clin Cancer Res. 2015;21:4234-42.

13. Zheng G, Du L, Yang X, Zhang X, Wang L, Yang Y, Li J, Wang C. Serum microRNA panel as biomarkers for early diagnosis of colorectal adenocarcinoma. Br J Cancer. 2014;111:1985-92.

14. Óscar R-G. Ana Álvarez-Castro, Rafael López-López, José Iglesias-Canle, María Mercedes SuárezCunqueiro and Laura Muinelo-Romay. Circulating microRNAs as Promising Biomarkers in Colorectal Cancer. Cancers. 2019;11:898.

15. Shen J, Stass SA, Jiang F. MicroRNAs as potential biomarkers in human solid tumors. Cancer Lett. 2013;329(2):125-36.

16. Toiyama Y, Takahashi M, Hur K, Nagasaka T, Tanaka K, Inoue $Y$, et al. Serum miR-21 as a diagnostic and prognostic biomarker in colorectal cancer. J Natl Cancer Inst. 2013;105(12):849-59.

17. Bresalier RS, Kopetz S, Brenner DE. Blood-based tests for colorectal cancer screening: do they threaten the survival of the FIT test? Dig Dis Sci. 2015;60(3):664-71.

18. Kosaka N, Iguchi H, Ochiyn T. Circulating microRNA in body fluid: a new potential biomarker for cancer diagnosis and prognosis. Cancer Sci. 2010;101:2087-92.

19. Montagnana M, Benati M, Danese E, Minicozzi AM, Paviati E, Gusella M, Pasini F, Bovo C, Guidi GC, Lippi G. Plasma expression levels of circulating miR-21 are not useful for diagnosing and monitoring colorectal cancer. Clin Lab. 2016;62(5):967-70.

20. Said E, Zidan A, Nawar A, Alhusseini N, Soliman E. Circulating Micro RNA- 21 and - 92a as Biomarkers of Colorectal Cancer. Afro-Egypt J Infect Endem Dis. 2017;7(4):247-57. 
21. Murphy G, Devesa SS, Cross AJ, Inskip PD, Mcglynn KA, Cook MB. Sex disparities in colorectal cancer incidence by anatomic subsite, race and age. Int J Cancer. 2011;128(7):166875.

22. Abotchie PN, Vernon SW, Du XL. Gender differences in colorectal cancer incidence in the United States, 1975-2006. J Womens Health (Larchmt). 2012;21(4):393-400.

23. Liu Q, Yang W, Luo Y, Hu S, Zhu L. Correlation between miR-21 and miR-145 and the incidence and prognosis of colorectal cancer. JBUON. 2018;23:29-35.

24. Vega AB, Pericay C, Moya I, et al. microRNA expression profile in stage III colorectal cancer: Circulating miR18a and miR-29a as promising biomarkers. Oncol Rep. 2013;30:320-6.

25. Schetter AJ, Leung SY, Sohn JJ, Zanetti KA, Bowman ED, Yanaihara N, et al. MicroRNA expression profiles associated with prognosis and therapeutic outcome in colon adenocarcinoma. JAMA. 2008;299(4):425-36.

26. Ghareib AF, Mohamed RH, Abd el-Fatah AR, Saadawy SF. Assessment of Serum MicroRNA-21 Gene Expression for Diagnosis and Prognosis of Colorectal Cancer. Journal of Gastrointestinal Cancer. 2019;3:1-6.

27. Elaguizy M, Sheta M, Ibrahim N, Eltaweel A, Mostafa A. Serum microRNA-18a, microRNA-21 and microRNA-92a as diagnostic markers in colorectal cancer patients. Journal of BU ON: Official Journal of the Balkan Union of Oncology. 2020;25(3):1443-8.

28. Liu GH, Zhou ZG, Chen R, Wang MJ, Li Y, Sun XF. Serum miR-21 and miR-92a as biomarkers in the diagnosis and prognosis of colorectal cancer. Tumor biology. 2013;34(4):2175-81.

29. Bastaminejad S, Taherikalani M, Ghanbari R, Akbari A, Shabab N, Saidijam M. Investigation of microRNA-21 expression levels in serum and stool as a potential non-invasive biomarker for diagnosis of colorectal cancer. Iran Biomed J. 2016;21:106-13.

30. Lu J, Getz G, Miska EA, Alvarez-Saavedra E, Lamb J, Peck D, et al. MicroRNA expression profiles classify human cancers. Nature. 2005;435(7043):834-8.

\section{Tables}

Table 1: Demographic data of enrolled groups

\begin{tabular}{llll} 
& Cases $(\mathrm{n}=50)$ & Control $(\mathrm{n}=25)$ & P value \\
\hline Age (years) & $46.74 \pm 11.65$ & $49.08 \pm 12.22$ & 0.42 \\
\hline Sex & & & 0.46 \\
Male & $36(72 \%)$ & $19(76 \%)$ & \\
Female & $14(28 \%)$ & $6(24 \%)$ & \\
\hline Smoking & $26(52 \%)$ & $12(48 \%)$ & 0.47 \\
\hline Family history of CRC & $9(18 \%)$ & $4(16 \%)$ & 0.55
\end{tabular}


Data expressed as frequency (percentage), mean (SD). P value was significant if $<0.05$

Table 2: Characteristics of the lesions among the enrolled patients

\begin{tabular}{ll} 
& $\mathrm{N}=50$ \\
\hline Size $(\mathrm{cm})$ & $4.86 \pm 1.51$ \\
$<5 \mathrm{~cm}$ & $38(76 \%)$ \\
$>5 \mathrm{~cm}$ & $12(24 \%)$ \\
\hline Site of the lesion & \\
Colon & $36(72 \%)$ \\
Rectum & $14(28 \%)$ \\
\hline TNM stage & \\
I-II & $14(28 \%)$ \\
III-IV & $36(72 \%)$ \\
\hline Histological type & \\
Differentiated & $32(64 \%)$ \\
Undifferentiated & $18(36 \%)$ \\
\hline Lymph metastasis & $19(38 \%)$ \\
\hline Distant metastasis & \\
Absent & $42(84 \%)$ \\
Liver metastasis & $5(10 \%)$ \\
Peritoneal metastasis & $3(6 \%)$ \\
\hline
\end{tabular}

Data expressed as frequency (percentage), mean (SD)

Table 3: Level of miRNA-21 gene expression among enrolled groups

\begin{tabular}{llll} 
& Cases $(\mathrm{n}=50)$ & Control $(\mathrm{n}=25)$ & P value \\
\hline MiRNA-21 $(\mathrm{u} / \mathrm{l})$ & $2.76 \pm 0.56$ & $0.71 \pm 0.16$ & $<0.001$ \\
Range & $1.50-3.70$ & $0.40-1$ &
\end{tabular}

Data expressed as mean (SD), range. $P$ value was significant if $<0.05$.

Table 4: miRNA-21 expression in patients based on clinicopathological parameters 


\begin{tabular}{|c|c|c|}
\hline & Mean \pm SD & $P$ value \\
\hline Size $(\mathrm{cm})$ & & 0.03 \\
\hline$<5 \mathrm{~cm}$ & $2.73 \pm 2.73$ & \\
\hline$>5 \mathrm{~cm}$ & $3.87 \pm 0.62$ & \\
\hline Site of the lesion & & 0.62 \\
\hline Colon & $2.74 \pm 0.58$ & \\
\hline Rectum & $2.82 \pm 0.52$ & \\
\hline TNM stage & & 0.04 \\
\hline$H-I I$ & $2.70 \pm 0.59$ & \\
\hline III-IV & $3.76 \pm 0.55$ & \\
\hline Histological type & & 0.96 \\
\hline Differentiated & $2.76 \pm 0.59$ & \\
\hline Undifferentiated & $2.76 \pm 0.50$ & \\
\hline Lymph metastasis & & 0.39 \\
\hline Yes & $2.67 \pm 0.46$ & \\
\hline No & $2.82 \pm 0.62$ & \\
\hline Liver metastasis & & 0.01 \\
\hline Yes & $3.70 \pm 0.23$ & \\
\hline No & $2.89 \pm 0.23$ & \\
\hline Peritoneal metastasis & & 0.33 \\
\hline Yes & $2.70 \pm 0.31$ & \\
\hline No & $2.77 \pm 0.61$ & \\
\hline
\end{tabular}

Data expressed as frequency (percentage), mean (SD). P value was significant if $<0.05$ Table 5: Performance of different markers in detection of CRC 


\begin{tabular}{llll} 
Indices & miRNA-21 & CA19-9 & CEA \\
\hline Sensitivity & $96 \%$ & $30 \%$ & $59 \%$ \\
\hline Specificity & $95 \%$ & $89 \%$ & $76 \%$ \\
\hline Positive predictive value & $98 \%$ & $71 \%$ & $66 \%$ \\
\hline Negative predictive value & $92 \%$ & $41 \%$ & $54 \%$ \\
\hline Cut off point & $>1.09$ & $>35$ & $>25$ \\
\hline Area under curve & 0.95 & 0.54 & 0.83
\end{tabular}

CRC: colo-rectal cancer; CEA: carcino-embryonic an

Table 6: Performance of different markers in detection of liver metastasis

\begin{tabular}{llll} 
Indices & miRNA-21 & CA19-9 & CEA \\
\hline Sensitivity & $100 \%$ & $60 \%$ & $80 \%$ \\
\hline Specificity & $87 \%$ & $86 \%$ & $30 \%$ \\
\hline Positive predictive value & $50 \%$ & $23 \%$ & $45 \%$ \\
\hline Negative predictive value & $100 \%$ & $97 \%$ & $70 \%$ \\
\hline Cut off point & $>2.67$ & $>39$ & $>19$ \\
\hline Area under curve & 0.89 & 0.59 & 0.53
\end{tabular}

Table 7: Performance of different markers in advanced TNM stage

\begin{tabular}{llll} 
Indices & miRNA-21 & CA19-9 & CEA \\
\hline Sensitivity & $100 \%$ & $41 \%$ & $80 \%$ \\
\hline Specificity & $84 \%$ & $84 \%$ & $76 \%$ \\
\hline Positive predictive value & $42 \%$ & $71 \%$ & $75 \%$ \\
\hline Negative predictive value & $100 \%$ & $61 \%$ & $78 \%$ \\
\hline Cut off point & $>2.67$ & $>34$ & $>13$ \\
\hline Area under curve & 0.89 & 0.57 & 0.79
\end{tabular}

\section{Supplementary Files}

This is a list of supplementary files associated with this preprint. Click to download. 
- supportinginformation3.docx

Page 19/19 